\title{
Adapting the Stage of Change model to investigate adolescent behavior related to reducing second hand smoke exposure*
}

\author{
Chris G. Richardson ${ }^{1}$, Jennifer Schwartz ${ }^{1 \#}$, Laura L. Struik ${ }^{2}$, Joan L. Bottorff ${ }^{2}$ \\ ${ }^{1}$ School of Population \& Public Health, University of British Columbia, Vancouver, Canada; \\ ${ }^{\#}$ Corresponding Author: Jennifer Schwartz@alumni.ucsd.edu \\ ${ }^{2}$ School of Nursing, University of British Columbia, Kelowna, Canada
}

Received 14 January 2013; revised 2 March 2013; accepted 12 April 2013

Copyright (C) 2013 Chris G. Richardson et al. This is an open access article distributed under the Creative Commons Attribution License, which permits unrestricted use, distribution, and reproduction in any medium, provided the original work is properly cited.

\begin{abstract}
Aims: Second hand smoke (SHS) exposure is increasingly recognized as a major public health concern. Assessing adolescents' motivational level to avoid SHS is vital to promote and reinforce reductions in SHS exposure. Methods: A brief measure based on the Stage of Change model was developed to characterize adolescents' behavior related to reducing SHS exposure and used to identify potential determinants of SHS stage of change. The sample consisted of 1172 adolescents aged 13 to 15 years who participated in an internet-based cohort study of youth in British Columbia, Canada. Results: Sixty-six percent of the adolescents reported they had consistently made efforts to reduce exposure to SHS for more than 6 months, while $19 \%$ did not intend to reduce their exposure to SHS in the next 6 months. Adolescents' SHS stage of change significantly differed by ethnicity, whether they had tried cigarettes, amount of tobacco smoked in their lifetime, parental and peer smoking statuses, past months' exposure to SHS, frequent smoking in the home, and home smoking restrictions (all $p<0.05$ ). Active smoking and more frequent exposure to SHS were associated with an increased probability of being in the pre-contemplation stage of change with regard to behavior related to reducing SHS exposure. Conclusion: This brief measure based
\end{abstract}

\footnotetext{
Funding: This research was supported by funding from the Canadian Breast Cancer Research Alliance and the Canadian Breast Cancer Foundation, and from the Canadian Institutes of Health Research to Dr. Richardson. Declaration of Interests: None of the authors report any competing interests.
}

on the Stage of Change model can be used in future studies to characterize adolescents' behavior around SHS. Adolescents who smoke or have parents and/or friends who smoke appear to be a population that could benefit from stagematched interventions designed to raise awareness of the risks associated with SHS for smokers and non-smokers, and ultimately reduce SHS exposure.

Keywords: Second Hand Smoke; Passive Smoke; Smoking; Stage of Change; Adolescents

\section{INTRODUCTION}

Second hand smoke (SHS) exposure is increasingly recognized as a vital public health concern in Canada, where non-smoking youth aged 12 to 19 experience the most SHS exposure [1]. Recent evidence indicates a causal link between long-term regular exposure to SHS and premenopausal breast cancer [2]. Furthermore, extensive evidence indicates that SHS exposure during childhood is associated with the development and exacerbation of asthma and other respiratory illnesses [3], reduced lung function [4], ear infections [5], cardiovascular effects [6], sleep difficulties [7], behavior problems [8], and increased risk of several cancers [9]. Consequently, further research on adolescents' exposure to and behavior around SHS is imperative to promote active management around SHS that will reduce harm.

To facilitate research on adolescents' behavior to reduce risks associated with exposure to SHS we used Prochaska's Stage of Change model [10] to create a brief measure that can be used to characterize adolescents' risk reduction behavior related to SHS. The core of Prochaska's 
Stage of Change model is based on the following five stages: 1) Pre-contemplation: no intention to change behavior in the foreseeable future; 2) Contemplation: being aware of the problem, and thinking about changing behavior; 3) Preparation: intention to change behavior in the next month, and have successfully tried to change behavior in the past year; 4) Action: behavior is changed in order to overcome a problem, which requires time and energy; and 5) Maintenance: prevent relapse, consolidate gains attained during action, and maintenance of action for $\geq 6$ months [10]. This model has been used to investigate and characterize numerous health behaviors among adolescents, including smoking cessation [11-13], substance abuse [12,14], sun protection [15], fruit and vegetable consumption [16], dietary adherence [17], contraceptive use [18], and physical activity [19]. For example, results from a study by Dino et al. indicated that adolescents' stage of change at baseline predicted smoking cessation intervention outcomes three months post-baseline [11]. Additionally, Evers et al. recently tailored an internet-delivered intervention to middle school students based on the Stage of Change model, which was shown to significantly reduce substance use (tobacco, alcohol, and other drugs) following the three-month intervention [12]. Adapting the Stage of Change model to produce a standardized tool for characterizing behavior related to reducing SHS exposure could have potential for informing the development and delivery of interventions focused on reducing SHS exposure.

The aim of this study was to: 1) develop a brief measure of risk reduction behavior related to SHS based on the Stage of Change model; 2) use this measure to characterize adolescents' behavior related to SHS exposure; and 3) identify potential determinants of SHS stage of change, with a focus on the impact of tobacco exposure.

\section{METHODS}

\subsection{Participants}

Participants were adolescents aged 13 to 15 years who participated in an internet-based cohort study of youth in British Columbia, Canada (The BC Adolescent Substance Use Survey [BASUS]). Students were recruited in the fall 2010 from 48 public secondary schools in BC via posters, advertisements, in-school newspapers, announcements, and printed material. Eligibility criteria were ability to read and complete the internet-based survey in English, and be 13 years of age or older. All participants provided informed consent, as well as written parental consent in schools requiring participants to provide parental consent. Upon completion of the survey, all students received a $\$ 25$ gift card. This study was approved by the University of British Columbia Behavioural Research Ethics Board.

\subsection{Measures}

Participant characteristics of age, gender, ethnicity, family income, tobacco exposure, and SHS exposure were assessed in the web-based questionnaire. The following measure based on Prochaska's Stage of Change model [10] assessed adolescents' stage of change (i.e., maintenance, action, preparation, contemplation and precontemplation) related to reducing exposure to SHS:

When you are exposed to second hand cigarette smoke do you consistently do things to reduce your exposure to the smoke? (Please check only one)

1) Yes, I have been for more than 6 months (MAINTENANCE).

2) Yes, I have been, but for less than 6 months (ACTION).

3) No, but I intend to in the next 30 days (PREPARATION).

4) No, but I intend to in the next 6 months (CONTEMPLATION).

5) No, and I do NOT intend to in the next 6 months (PRE-CONTEMPLATION).

Based on responses to this question, adolescents were categorized as being in a particular stage with regard to reducing their exposure to SHS.

\subsection{Statistical Analysis}

Univariate analyses (Pearson Chi-square tests) were performed to examine key covariates (e.g. ethnicity) by reported behavior to reduce SHS exposure. An alpha level of $p<0.05$ (2-tailed) was used to indicate statistical significance, and all statistical analyses were conducted using IBM SPSS Statistics 19.0.

\section{RESULTS}

Among the BASUS sample of adolescents who participated in the online questionnaire in the fall $2010(\mathrm{n}=$ 1577), $74 \%(\mathrm{n}=1172)$ completed the measure that assessed their stage of change related to reducing exposure to SHS; the 405 students who did not complete our measure were dropped from analyses. Among these 1172 students, $55 \%$ were female, $53 \%$ were Caucasian, and $75 \%$ reported an average family income. The majority of these adolescents had non-smoking parents (70\%) and friends $(78 \%)$, reported that no one smoked in their home every day or almost every day (87\%), and reported home smoking restrictions $(86 \%)$. Thirteen percent had tried smoking, and among those who had tried smoking, the majority $(75 \%)$ had smoked $\leq 25$ cigarettes. Characteristics of the sample of adolescents by stage of change related to reducing SHS exposure are presented in Table 1. The majority $(66 \%)$ of adolescents were classified as being in the maintenance stage, although proportions 
Table 1. Characteristics of adolescents $(\mathrm{N}=1172)$ by stage of change related to reducing exposure to secondhand smoke.

\begin{tabular}{|c|c|c|c|c|c|c|}
\hline & & \multicolumn{5}{|c|}{ Stage of Change } \\
\hline & & Maintenance & Action & Preparation & Contemplation & Pre-contemplation \\
\hline & Number (\%) & $769(66 \%)$ & $108(9 \%)$ & $32(3 \%)$ & $42(4 \%)$ & $221(19 \%)$ \\
\hline \multicolumn{7}{|c|}{ Demographics } \\
\hline \multirow{3}{*}{ Gender } & Male $(\mathrm{n}=520)$ & $331(64 \%)$ & $54(10 \%)$ & $13(3 \%)$ & $16(3 \%)$ & $106(20 \%)$ \\
\hline & Female $(\mathrm{n}=623)$ & $423(68 \%)$ & $51(8 \%)$ & $18(3 \%)$ & $25(4 \%)$ & $106(17 \%)$ \\
\hline & Caucasian $(\mathrm{n}=615)$ & $417(68 \%)$ & $47(8 \%)$ & $18(3 \%)$ & $25(4 \%)$ & $108(18 \%)$ \\
\hline \multirow{2}{*}{ Ethnicity $^{*}$} & Aboriginal $(\mathrm{n}=169)$ & $102(60 \%)$ & $21(12 \%)$ & $7(4 \%)$ & $4(2 \%)$ & $35(21 \%)$ \\
\hline & $A \operatorname{sian}(n=334)$ & $219(66 \%)$ & $36(11 \%)$ & $5(2 \%)$ & $8(2 \%)$ & $66(20 \%)$ \\
\hline \multirow{4}{*}{$\begin{array}{l}\text { Family Income } \\
\text { (self-reported) }\end{array}$} & Other $(n=36)$ & $22(61 \%)$ & $3(8 \%)$ & 0 & $5(14 \%)$ & $6(17 \%)$ \\
\hline & $\begin{array}{l}\text { Below average } \\
\quad(\mathrm{n}=55)\end{array}$ & $29(53 \%)$ & $8(15 \%)$ & $2(4 \%)$ & $2(4 \%)$ & $14(26 \%)$ \\
\hline & Average $(\mathrm{n}=821)$ & $548(67 \%)$ & $76(9 \%)$ & $19(2 \%)$ & $32(4 \%)$ & $146(18 \%)$ \\
\hline & $\begin{array}{l}\text { Above average } \\
\qquad(\mathrm{n}=218)\end{array}$ & $144(66 \%)$ & $20(9 \%)$ & $8(4 \%)$ & $6(3 \%)$ & $40(18 \%)$ \\
\hline \multicolumn{7}{|c|}{ Tobacco exposure } \\
\hline \multirow{3}{*}{$\begin{array}{l}\text { Have tried smoking } \\
\text { tobacco }\end{array}$} & Yes $(\mathrm{n}=151)$ & $64(42 \%)$ & $17(11 \%)$ & $11(7 \%)$ & $10(7 \%)$ & $49(33 \%)$ \\
\hline & No $(n=1021)$ & $705(69 \%)$ & $91(9 \%)$ & $21(2 \%)$ & $32(3 \%)$ & $172(17 \%)$ \\
\hline & $\begin{array}{c}\leq 25 \text { cigarettes } \\
(\mathrm{n}=109)\end{array}$ & $52(48 \%)$ & $13(12 \%)$ & $10(9 \%)$ & $7(6 \%)$ & $27(25 \%)$ \\
\hline \multirow[t]{2}{*}{$\begin{array}{l}\text { Amount smoked in } \\
\text { lifetime }\end{array}$} & $\begin{array}{l}26-99 \text { cigarettes } \\
\qquad(\mathrm{n}=15)\end{array}$ & $5(33 \%)$ & $1(7 \%)$ & $1(7 \%)$ & $2(13 \%)$ & $6(40 \%)$ \\
\hline & $\begin{array}{c}\text { More than } 100 \\
\text { cigarettes }(n=21)\end{array}$ & $5(24 \%)$ & $3(14 \%)$ & 0 & $1(5 \%)$ & $12(57 \%)$ \\
\hline \multicolumn{7}{|c|}{ Secondhand smoke exposure } \\
\hline \multirow{2}{*}{ Parent(s) smoke ${ }^{\dagger}$} & Yes $(n=311)$ & $185(60 \%)$ & $37(12 \%)$ & $11(4 \%)$ & $9(3 \%)$ & $69(22 \%)$ \\
\hline & No $(n=729)$ & $507(70 \%)$ & $59(8 \%)$ & $15(2 \%)$ & $29(4 \%)$ & $119(16 \%)$ \\
\hline \multirow{2}{*}{ Friends who smoke } & Yes $(n=196)$ & $96(49 \%)$ & $31(16 \%)$ & $8(4 \%)$ & $9(5 \%)$ & $52(27 \%)$ \\
\hline & No $(n=696)$ & $504(72 \%)$ & $52(8 \%)$ & $16(2 \%)$ & $17(2 \%)$ & $107(15 \%)$ \\
\hline \multirow{3}{*}{$\begin{array}{l}\text { Overall past months' } \\
\text { exposure to SHS }\end{array}$} & $\begin{array}{l}\text { Every/almost every } \\
\text { day }(\mathrm{n}=179)\end{array}$ & $103(58 \%)$ & $22(12 \%)$ & $7(4 \%)$ & $10(6 \%)$ & $37(21 \%)$ \\
\hline & $\begin{array}{l}\text { At least once a week } \\
\qquad(\mathrm{n}=324)\end{array}$ & $221(68 \%)$ & $34(11 \%)$ & $13(4 \%)$ & $15(5 \%)$ & $41(13 \%)$ \\
\hline & $\begin{array}{l}\text { At least once in past } \\
\text { month }(\mathrm{n}=491)\end{array}$ & $348(71 \%)$ & $44(9 \%)$ & $8(2 \%)$ & $13(3 \%)$ & $78(16 \%)$ \\
\hline \multirow{3}{*}{$\begin{array}{c}\text { Does anyone smoke } \\
\text { in your home every } \\
\text { day or almost every } \\
\text { day? }^{\dagger}\end{array}$} & Never $(n=164)$ & $91(56 \%)$ & $7(4 \%)$ & $4(2 \%)$ & $3(2 \%)$ & $59(36 \%)$ \\
\hline & Yes $(n=148)$ & $83(56 \%)$ & $21(14 \%)$ & $9(6 \%)$ & $2(1 \%)$ & $33(22 \%)$ \\
\hline & No $(n=1007)$ & $681(68 \%)$ & $84(8 \%)$ & $23(2 \%)$ & $40(4 \%)$ & $179(18 \%)$ \\
\hline \multirow{2}{*}{$\begin{array}{l}\text { Restrictions against } \\
\text { smoking in home? }^{\dagger}\end{array}$} & Yes $(\mathrm{n}=963)$ & $656(68 \%)$ & $81(8 \%)$ & $25(3 \%)$ & $34(4 \%)$ & $167(17 \%)$ \\
\hline & No $(n=159)$ & $82(52 \%)$ & $23(15 \%)$ & $6(4 \%)$ & $7(4 \%)$ & $41(26 \%)$ \\
\hline
\end{tabular}

${ }_{\mathrm{p}}^{\mathrm{p}}<0.05 ;{ }^{\dagger} \mathrm{p}<0.01 ;{ }^{\dagger} \mathrm{p}<0.001 ; \mathrm{p}$-values are based on Pearson Chi-square test.

varied according to smoking and SHS exposure.

Adolescents' stage of change with regard to behavior around SHS significantly differed by ethnicity $(\mathrm{p}<0.05)$, whether they had tried cigarettes $(\mathrm{p}<0.001)$, amount of 
tobacco smoked in their lifetime $(\mathrm{p}<0.001)$, peer smoking status $(\mathrm{p}<0.001)$, parental smoking status $(\mathrm{p}<0.01)$, past months' exposure to SHS ( $\mathrm{p}<0.001$ ), frequent smoking in the home $(\mathrm{p}<0.01)$, and home smoking restrictions $(\mathrm{p}<0.01)$. For example, a greater proportion of Aboriginal students were in the pre-contemplation stage compared to Caucasian students $(21 \%$ vs. $18 \%)$. Thirtythree percent of adolescents who had tried smoking were in the pre-contemplation stage compared to $17 \%$ of those who had never tried smoking. Among adolescents who had tried tobacco, the more they had smoked, the more likely they were to be in the pre-contemplation stage (e.g., among those who reported smoking $>100$ cigarettes, $57 \%$ were in the pre-contemplation stage compared to $25 \%$ of those who reported smoking $\leq 25$ cigarettes). Among adolescents with friends who smoke, $27 \%$ were in the pre-contemplation stage compared to $15 \%$ of adolescents who reported not having friends who smoke. Similarly, $22 \%$ of adolescents who reported having a parent who smokes were in the pre-contemplation stage compared to $16 \%$ of adolescents who reported that their parents did not smoke. The greater the adolescents' exposure to SHS in the past month, the more likely they were to be in the pre-contemplation stage (e.g., 21\% of those who were exposed every day or almost every day were in the pre-contemplation stage compared to $16 \%$ of those who were exposed at least once in the past month). A greater proportion of adolescents who reported that someone smoked in their home every day or almost every day were in the pre-contemplation stage compared to adolescents who reported that no one smoked in their home every day or almost every day (22\% vs. $18 \%$ ). Lastly, adolescents who reported no home smoking restrictions had a significantly greater proportion of pre-contemplators compared to those who had home smoking restrictions $(26 \%$ vs. $17 \%)$.

\section{DISCUSSION}

By adapting Prochaska's Stage of Change Model [10], we created a measurement tool that can be used to assess adolescents' behavior around SHS. Based on the information derived from this tool, the majority of adolescents in our sample were in the maintenance stage with regard to behavior related to reducing SHS exposure, meaning they had been consistently making an effort to reduce their exposure for more than 6 months. Nonetheless, adolescents' stage of change with regard to behavior related to SHS significantly differed by ethnicity, whether they had tried cigarettes, amount of tobacco smoked in their lifetime, parental and peer smoking statuses, past months' exposure to SHS, frequent smoking in the home, and home smoking restrictions.

A greater proportion of adolescents who were Abo- riginal, had tried smoking, reported having parents or friends who smoked, were exposed to SHS every day or almost every day in the past month, reported that someone smoked in their home every day or almost every day, and did not have home smoking restrictions were in the pre-contemplation stage compared to Caucasians, those who had never tried smoking, reported not having parents or friends who smoked, were exposed to SHS at least once in the past month, reported that no one smoked in their home every day or almost every day, and had home smoking restrictions, respectively. Among adolescents who had tried tobacco, the more they had smoked, the more likely they were to be in the pre-contemplation stage, thereby suggesting a dose-response relationship between amount of tobacco smoked and the likelihood of being in the pre-contemplation stage with regard to SHS risk reduction behavior.

Results of this analysis are consistent with Prochaska's Stage of Change model in that adolescents with greater exposure to first-hand and second-hand tobacco smoke were more likely to be in the pre-contemplation stage with regard to their motivational level for engaging in behaviors that reduce exposure to SHS. It could be hypothesized that among these exposed adolescents, social norms and the desire to "fit in" result in decisional imbalance in which the cons associated with doing things to reduce exposure to tobacco smoke outweigh the pros, thus resulting in reduced motivation to avoid SHS. Our brief measure could be validated and used in future assessments and stage-matched interventions among adolescents, with the goal of ultimately reducing SHS exposure.

This analysis is not without limitations. Although the sample size associated with this study was quite large, generalizability of the present findings to other age groups and ethnicities is limited, especially if they contain a substantially larger number of adolescents who smoke. Additionally, because all measures in the current analysis were based on self-report, social desirability could potentially have biased the results.

\section{CONCLUSION}

This analysis indicates that adolescents in a "prosmoking" environment - those who have smoked in the past or currently smoke, and those who have parents or friends who smoke-represent a population that could benefit from stage-matched interventions focused on reducing SHS exposure. For example, raising awareness of the long- and short-term health effects of smoking, and the impact it has socially and environmentally [20], as well as emphasizing the benefits of smoke-free behaviour [21] are strategies that could be employed for targeting adolescents in the pre-contemplation stage. In summary, the brief measure based on the Stage of 
Change model has the potential to be used in future studies to characterize adolescents' behavior related to SHS exposure, and in turn inform the tailoring or design of SHS reduction interventions.

\section{REFERENCES}

[1] Canadian Partnership against Cancer (2012) Second-hand smoke and cancer.

http://www.cancerview.ca/idc/groups/public/documents/w ebcontent/crc snapshot 9.pdf

[2] Johnson, K.C., Miller, A.B., Collishaw, N.E., Palmer, J.R., Hammond, S.K., Salmon, A.G., et al. (2009) Active smoking and second-hand smoke increase breast cancer risk: The report of the Canadian Expert Panel on Tobacco Smoke and Breast Cancer Risk. Tobacco Control, 20, e2. doi:10.1136/tc.2010.035931

[3] Oberg, M., Jaakkola, M.S., Woodward, A., Peruga, A. and Prüss-Ustün, A. (2011) Worldwide burden of disease from exposure to second-hand smoke: A retrospective analysis of data from 192 countries. The Lancet, 377, 139-146. doi:10.1016/S0140-6736(10)61388-8

[4] Stocks, J. and Dezateux, C. (2003) The effect of parental smoking on lung function and development during infancy. Respirology, 8, 266-285. doi:10.1046/j.1440-1843.2003.00478.x

[5] Jones, L.L., Hassanien, A., Cook, D.G., Britton, J. and Leonardi-Bee, J. (2012) Parental smoking and the risk of middle ear disease in children: A systematic review and meta-analysis. Archives of Pediatrics \& Adolescent Medicine, 166, 18-27. doi:10.1001/archpediatrics.2011.158

[6] Geerts, C.C., Bots, M.L., Van der Ent, C.K., Grobbee, D.E. and Uiterwaal, C.S.P.M. (2012) Parental smoking and vascular damage in their 5-year-old children. Pediatrics, 129, 45-54. doi:10.1542/peds.2011-0249

[7] Yolton, K., Xu, Y., Khoury, J., Succop, P., Lanphear, B., Beebe, D.W., et al. (2010) Associations between secondhand smoke exposure and sleep patterns in children. Pediatrics, 125, e261-e268. doi:10.1542/peds.2009-0690

[8] Twardella, D., Bolte, G., Fromme, H., Wildner, M. and Von Kries, R. (2010) Exposure to second-hand tobacco smoke and child behaviour-Results from a cross-sectional study among preschool children in Bavaria. Acta Paediatrica, 99, 106-111.

[9] Milne, E., Greenop, K.R., Scott, R.J., Bailey, H.D., Attia, J., Dalla-Pozza, L., et al. (2012) Parental prenatal smoking and risk of childhood acute lymphoblastic leukemia. American Journal of Epidemiology, 175, 43-53. doi:10.1093/aje/kwr275

[10] Prochaska, J., Velicer, W., Rossi, J., Goldstein, M., Marcus, B., Rakowski, W., et al. (1994) Stages of change and decisional balance for 12 problem behaviors. Health Psychology, 13, 39-46. doi:10.1037/0278-6133.13.1.39

[11] Dino, G., Kamal, K., Horn, K., Kalsekar, I. and Fernandes, A. (2004) Stage of change and smoking cessation out- comes among adolescents. Addictive Behaviors, 29, 935940. doi:10.1016/j.addbeh.2004.01.004

[12] Evers, K.E., Paiva, A.L., Johnson, J.L., Cummins, C.O., Prochaska, J.O., Prochaska, J.M., et al. (2012) Results of a transtheoretical model-based alcohol, tobacco and other drug intervention in middle schools. Addictive Behaviors, 37, 1009-1018. doi:10.1016/j.addbeh.2012.04.008

[13] Pallonen, U.E., Velicer, W.F., Prochaska, J.O., Rossi, J.S., Bellis, J.M., Tsoh, J.Y., et al. (1998) Computer-based smoking cessation interventions in adolescents: Description, feasibility, and six-month follow-up findings. Substance Use \& Misuse, 33, 935-965. doi: 10.3109/10826089809056250

[14] Callaghan, R.C., Hathaway, A., Cunningham, J.A., Vettese, L.C., Wyatt, S. and Taylor, L. (2005) Does stage-ofchange predict dropout in a culturally diverse sample of adolescents admitted to inpatient substance-abuse treatment? A test of the transtheoretical model. Addictive Behaviors, 30, 1834-1847. doi:10.1016/j.addbeh.2005.07.015

[15] Adams, M.A., Norman, G.J., Hovell, M.F., Sallis, J.F. and Patrick, K. (2009) Reconceptualizing decisional balance in an adolescent sun protection intervention: Mediating effects and theoretical interpretations. Health Psychology, 28, 217-225. doi:10.1037/a0012989

[16] Di Noia, J., Schinke, S.P., Prochaska, J.O. and Contento, I.R. (2006) Application of the transtheoretical model to fruit and vegetable consumption among economically disadvantaged African-American adolescents: Preliminary findings. American Journal of Health Promotion, 20, 342-348. doi:10.4278/0890-1171-20.5.342

[17] Berg-Smith, S.M., Stevens, V.J., Brown, K.M., Van Horn, L., Gernhofer, N., Peters, E., et al. (1999) A brief motivational intervention to improve dietary adherence in adolescents. Health Education Research, 14, 399-410. doi:10.1093/her/14.3.399

[18] Grimley, D.M., Prochaska, J.O., Velicer, W.F. and Prochaska, G.E. (1995) Contraceptive and condom use adoption and maintenance: A stage paradigm approach. Health Education and Behavior, 22, 20-35. doi:10.1177/109019819502200104

[19] Nigg, C.R. and Courneya, K.S. (1998) Transtheoretical model: Examining adolescent exercise behavior. Journal of Adolescent Health, 22, 214-224. doi:10.1016/S1054-139X(97)00141-9

[20] Prokhorov, A.V., Kelder, S.H., Shegog, R., Conroy, J.L., Murray, N., Peters, R., et al. (2010) Project ASPIRE: An interactive, multimedia smoking prevention and cessation curriculum for culturally diverse high school students. Substance Use \& Misuse, 45, 983-1006. doi:10.3109/10826080903038050

[21] Cornacchione, J. and Smith, S.W. (2012) The effects of message framing within the stages of change on smoking cessation intentions and behaviors. Health Communication, 27, 612-622. doi:10.1080/10410236.2011.619252 